medRxiv preprint doi: https://doi.org/10.1101/2020.05.29.20117374; this version posted June 8, 2020. The copyright holder for this preprint

(which was not certified by peer review) is the author/funder, who has granted medRxiv a license to display the preprint in perpetuity.

All rights reserved. No reuse allowed without permission.

\title{
Title: Intracortical Microstimulation Elicits Human Fingertip Sensations
}

Authors: Matthew S. Fifer ${ }^{1 * \dagger,}$ David P. McMullen ${ }^{2 \dagger}$, Tessy M. Thomas ${ }^{3}$, Luke E. Osborn ${ }^{1}$, Robert W. $\mathrm{Nickl}^{4}$, Daniel N. Candrea ${ }^{3}$, Eric A. Pohlmeyer ${ }^{1}$, Margaret C. Thompson ${ }^{1}$, Manuel Anaya ${ }^{4}$, Wouter Schellekens $^{5}$, Nick F. Ramsey ${ }^{5}$, Sliman J. Bensmaia ${ }^{6}$, William S. Anderson ${ }^{7}$, Brock A. Wester ${ }^{1}$, Nathan E. Crone ${ }^{8}$, Pablo A. Celnik ${ }^{4}$, Gabriela L. Cantarero ${ }^{4}$, Francesco V. Tenore ${ }^{1}$

\section{Affiliations:}

${ }^{1}$ Research and Exploratory Development Department, Johns Hopkins University Applied Physics Laboratory, Laurel, MD, 20723, USA

${ }^{2}$ National Institute of Mental Health, National Institutes of Health, Bethesda, MD, 20892, USA

${ }^{3}$ Department of Biomedical Engineering, Johns Hopkins University, Baltimore, MD, 21205, USA

${ }^{4}$ Department of Physical Medicine and Rehabilitation, Johns Hopkins University, Baltimore, MD, 21205, USA

${ }^{5}$ UMC Utrecht Brain Center, Utrecht, Netherlands

${ }^{6}$ Department of Organismal Biology and Anatomy, University of Chicago, Chicago, IL, 60637, USA

${ }^{7}$ Department of Neurosurgery, Johns Hopkins University, Baltimore, MD, 21205, USA

${ }^{8}$ Department of Neurology, Johns Hopkins University, Baltimore, MD, 21205, USA

*Please direct inquiries to: matthew.fifer@jhuapl.edu

†These authors contributed equally to this work

One Sentence Summary: Sensations localized to fingertips on both hands were elicited by directly stimulating microelectrodes, targeted via a novel intra-operative mapping technique, in the somatosensory cortices of a participant with spinal cord injury.

\section{Abstract:}

The restoration of cutaneous sensation to fingers and fingertips is critical to achieving dexterous prosthesis control for individuals with sensorimotor dysfunction. However, localized and reproducible fingertip sensations in humans have not been reported via intracortical microstimulation (ICMS) in humans. Here, we show that ICMS in a human participant was capable of eliciting percepts in 7 fingers spanning both hands, including 6 fingertip regions (i.e., 3 on each hand). Median percept size was estimated to include 1.40 finger or palmar segments (e.g., one segment being a fingertip or the section of upper palm below a finger). This was corroborated with a more sensitive manual marking technique where median percept size corresponded to roughly $120 \%$ of a fingertip segment. Percepts showed high intra-day consistency, including high performance (99\%) on a blinded finger discrimination task. Across days, there was more variability in percepts, with $75.8 \%$ of trials containing the modal finger or palm region for the stimulated electrode. These results suggest that ICMS can enable the delivery of localized fingertip sensations during object manipulation by neuroprostheses. 
medRxiv preprint doi: https://doi.org/10.1101/2020.05.29.20117374; this version posted June 8, 2020. The copyright holder for this preprint

(which was not certified by peer review) is the author/funder, who has granted medRxiv a license to display the preprint in perpetuity.

All rights reserved. No reuse allowed without permission.

\section{Introduction}

Adding to the loss of motor function, the loss of finger sensation presents many obstacles for patients with spinal cord injury (SCI). Beyond the inability to directly sense physical properties of objects, the loss of cutaneous sensation impairs patients' ability to manipulate objects (1-4), as many of an object's attributes (e.g., weight, friction, geometry beyond the line of sight) are not visually available. Fingertip sensation plays a particularly critical role in dexterous object manipulation (5). Indeed, the fingertips account for the majority of contact events (6), are the most densely innervated region of the body along with the lips $(7,8)$, and have the most disproportionately large footprint in somatosensory cortex (9).

Intracortical microstimulation (ICMS) of somatosensory cortex has the potential to restore sensation to individuals with somatosensory impairments. ICMS has been shown to evoke percepts in non-human primates (NHPs), who can discriminate pulse trains that differ in frequency (10-13) and intensity (13, 14). Two recent studies of human responses to ICMS provided key insights into the subjective nature of these percepts, with one study reporting cutaneous sensations projected to the palm and index finger (15), while the other reported a mix of cutaneous and proprioceptive percepts distributed over the arm and hand (16). In both studies, stimulation was delivered to the postcentral gyrus, with differences in projected field location and quality of sensations likely due to differences in the locations of the arrays within the somatosensory homunculus. Stimulation through electrocorticographic (ECoG) electrodes in humans has also elicited hand sensations (17-19), though these sensations are usually less localized and often mixed with evoked movements.

Sensory signals provided via neural stimulation can be also used to guide and improve behavior in brainmachine interfaces (BMI). In studies with NHPs, ICMS was used to instruct movement directions $(20$ $22)$, to detect and discriminate indentations delivered to a prosthetic finger $(13,23)$, differentiate virtual objects $(11,24)$, and differentiate textures $(25)$. In studies with human BMI users, completion times for activities of daily living (ADLs) were shown to improve when tactile feedback was provided, either via ICMS (26) or non-invasive stimulation in the periphery (27). In amputees equipped with myoelectrically controlled bionic hands, delivery of sensory feedback via noninvasive $(28,29)$ or invasive $(30-32)$ nerve stimulation can improve performance on object grasping and manipulation tasks. The ability to decode individual finger movements from cortex in NHPs (33) and humans $(34,35)$, provides additional impetus to explore methods for providing fingertip percepts, with the ultimate goal of providing a fully dexterous and natural prosthetic hand for patients.

In the present study, we delivered ICMS in the finger areas of somatosensory cortex in both hemispheres through microelectrode implants in a patient with incomplete SCI (C5-C6 ASIA B). Finger regions were targeted due to their relevance to dexterous motor control. After implantation, we catalogued the location of the ICMS-evoked percepts with blinded assessments to characterize their spatial distribution and reliability. Our results demonstrate that fingertip percepts can be elicited via ICMS on the surface of the postcentral gyrus, a promising step towards providing naturalistic tactile feedback during object manipulation with prosthetic hands.

\section{Results}

Intraoperative functional mapping and surgical implant targeting

A 48-year-old male with C5 (sensory), C6 (motor) with American Spinal Injury Association (ASIA) Impairment Scale Grade B tetraplegia was implanted with six microelectrode arrays - four in left hemisphere, two in right hemisphere. Two of the arrays in the left hemisphere and one in the right were 
medRxiv preprint doi: https://doi.org/10.1101/2020.05.29.20117374; this version posted June 8, 2020. The copyright holder for this preprint (which was not certified by peer review) is the author/funder, who has granted medRxiv a license to display the preprint in perpetuity.

All rights reserved. No reuse allowed without permission.

implanted in primary somatosensory cortex and used primarily to deliver stimulation; the other two were implanted in primary motor cortex used for recording. Arrays were implanted in pairs consisting of one 96-channel recording ( $4 \mathrm{~mm} x 4 \mathrm{~mm}$, platinum tips) and one 32-channel stimulating array ( $4 \mathrm{~mm} x$ $2.4 \mathrm{~mm}, 400 \mathrm{um}$ pitch, custom population within $6 \times 10$ configuration, with sputtered iridium oxide film, SIROF, tips). Each array pair was wired to a skull-fixed transcutaneous metal pedestal to enable wired interface to the recording and stimulating hardware.

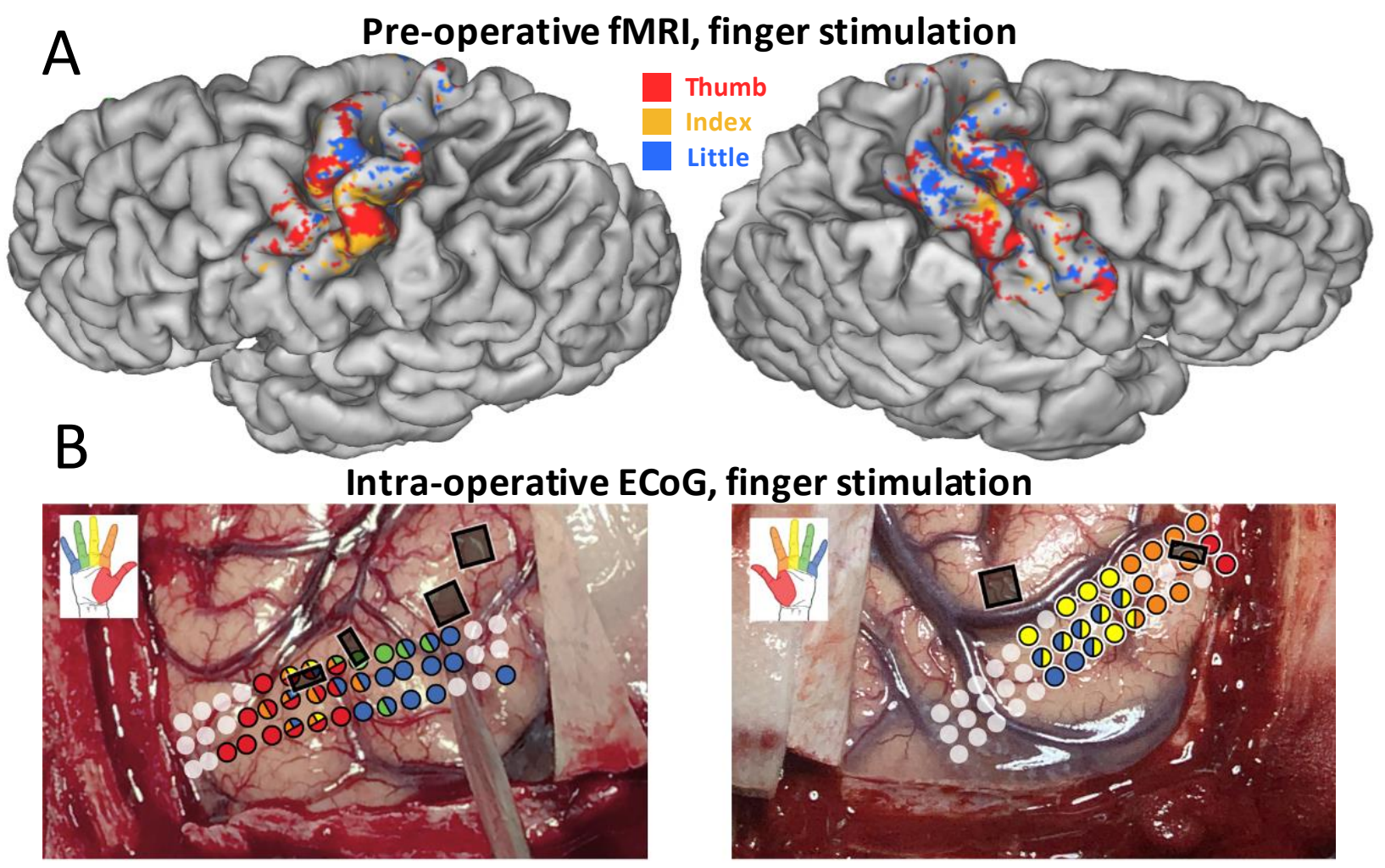

Figure 1. Pre- and Intra-operative Maps of Sensation. (A) The pre-operative fMRI results are shown for mechanical stimulation of the thumb, index, and little fingers on both hemispheres; colors are shown only for the most significant activation in the case of overlapping responses. (B) ECoG vibrational stimulation mapping results and array target locations generated intra-operatively. Colored circles denote electrodes with significant high gamma modulation, manually filtered for most salient results. Black squares and rectangles denote target implantation locations as provided to the neurosurgeon by the mapping team.

To inform the neurosurgical placement of the microelectrode arrays, we employed a novel approach to intraoperatively generate spatiotemporal maps of neural responses to mechanical stimuli delivered to the subject's fingertips. Pre-operative 7T functional magnetic resonance imaging (fMRI) of mechanical finger stimulations provided an initial estimate of finger representations in S1 (Fig. 1A). Using structural and functional information these scans, confirmed by intraoperative visual landmarks, we placed a highdefinition electrocorticography $(\mathrm{ECoG})$ grid $(3 \times 21$ with $3 \mathrm{~mm}$ inter-electrode spacing) on the postcentral gyrus. During the surgery, we stimulated the subject's fingers mechanically with a vibratory motor while we recorded the neural responses - specifically in the high gamma band $(70-110 \mathrm{~Hz})(36,37)$ - and displayed these as spatiotemporal maps. From these maps, finger-specific electrodes were identified and co-registered to the gyral surface anatomy manually using photographs of the brain taken before and after grid placement (Fig. 1B). This process was performed on each hemisphere, and a summary of the results was provided to the neurosurgeon to inform implantation targets. The stimulating arrays 
medRxiv preprint doi: https://doi.org/10.1101/2020.05.29.20117374; this version posted June 8, 2020. The copyright holder for this preprint (which was not certified by peer review) is the author/funder, who has granted medRxiv a license to display the preprint in perpetuity.

All rights reserved. No reuse allowed without permission.

implanted in the left hemisphere were targeted at thumb/index and middle/ring finger representations. The right hemisphere stimulating arrays were targeted at thumb/index representations.

A clear somatotopic gradient was observed in the tactile responses observed intra-operatively (Fig. 1B), with representations of the thumb located laterally relative to those of the little finger. These results are consistent with the expected spatial representations of individual fingers and with the ICMS-evoked percepts catalogued subsequently.
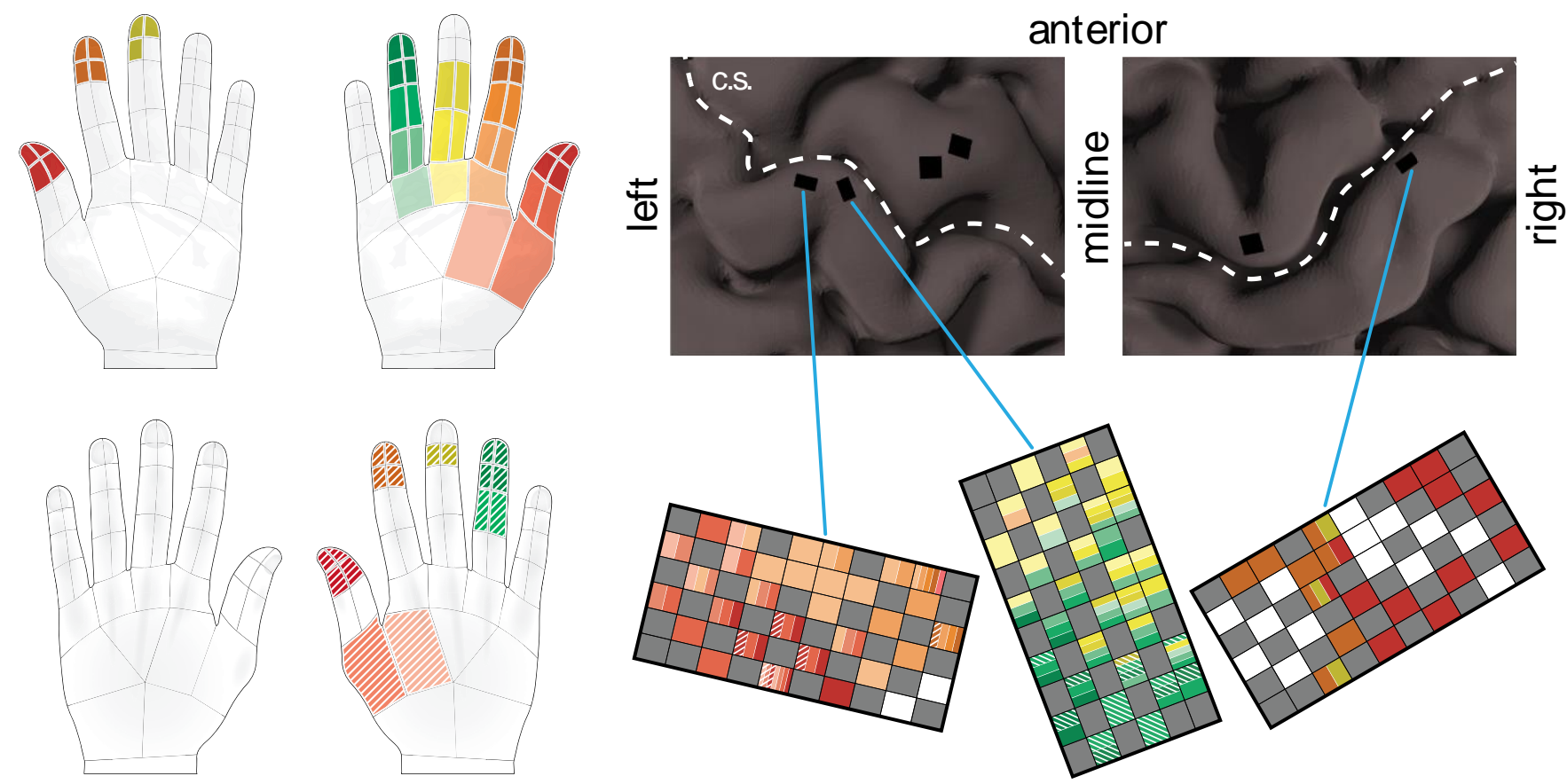

Figure 2. ICMS Projected Field Map. (A) Portions of the hand that were reported as part of a percept, for any single electrode on multiple days. Hue denotes finger, saturation denotes finger segment, and fletching denotes a dorsal hand percept. (B) For each electrode on the array, the set of colors present within the square corresponds to a finger segment in (A) that was reported for that electrode. Colored array maps refer to their reconstructed positions and orientations on the MRI (top).

\section{Projected fields elicited by ICMS}

Beginning 25 days after implantation, all 96 stimulating electrodes across 3 arrays were stimulated individually and the participant was asked to report the projected field location(s) using an image of the hand (Fig. S2A). Projected field locations were obtained from a mix of full array sweeps and short checks before longer tasks across 25 sessions spanning the first year after implantation; individual electrodes were surveyed between 4 and 16 times. Projected fields that were elicited on two or more separate days for a given electrode over the course of the study are shown in Fig. 2A. The participant reported stimulated sensations projected to six fingertips (right thumb, index, ring fingertips; left thumb, index, middle) and seven fingers (with the addition of the right middle finger). A number of percepts were reported on the dorsal side of the right hand, frequently alongside concomitant palmar sensations. Dorsal hand and finger percepts were concentrated in the caudal aspects of the left hemisphere arrays (Fig. 2B).

Stimulation early after implantation primarily led to electrical sensations. Later in the study (>14 weeks post-implantation), percepts were reported to primarily consist of pressure sensations - either similar to an externally applied pressure or a pressure seeming to originate from within (i.e., the subject likened 
medRxiv preprint doi: https://doi.org/10.1101/2020.05.29.20117374; this version posted June 8, 2020. The copyright holder for this preprint (which was not certified by peer review) is the author/funder, who has granted medRxiv a license to display the preprint in perpetuity.

All rights reserved. No reuse allowed without permission.

this to a "throb"). A moderate percentage ( $20 \%)$ of sensations were also reported to contain a "pins and needles' sensations, with only rare reports of any other type of sensation..

Percepts on both sides of the hand exhibited the expected finger somatotopic gradient from ring or middle finger (medially) to thumb (laterally) and fingertips were concentrated on the caudal portion of the left hemisphere arrays, near the crown of the postcentral gyrus (Fig. 2B). All reported percepts elicited from the right hemisphere array were located in the fingertip, so no gradient by finger segment was observed.

To quantify percept size and overlap, the hand was divided into phalanges, palmar pads, and corresponding dorsal regions (Fig. S2). Across all stimulations that elicited a detectable percept, the median percept for a single electrode included 1.40 finger or hand segments. As a crude metric of overlap, the mean number of electrodes which elicited stimulations in a given finger segment (i.e., expected value for a given day) was 2.2, with maximum of 11.7 electrodes eliciting sensations in the palmar square directly below index finger (Fig. S3).

\section{Discrimination of finger location stimulation}
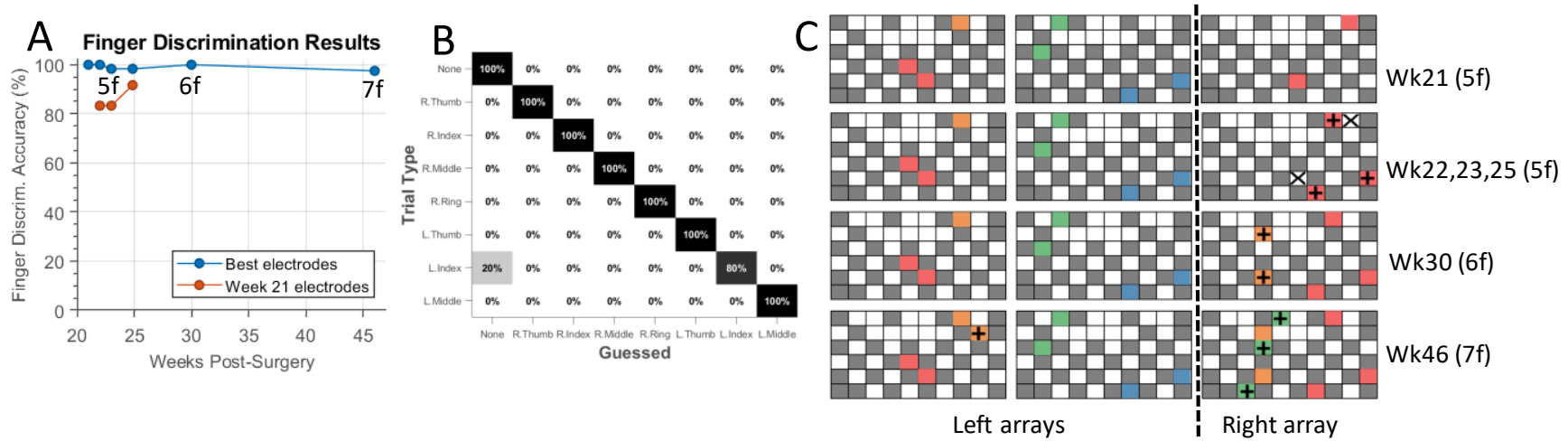

Figure 3. Finger Discrimination Results. (A) Finger Discrimination test results shown. Blue trace is the "best" electrodes chosen for each day. Orange trace is a short 3-week experiment re-using the same sites as the first week of the experiment (21 weeks post-surgery). (B) Confusion matrix corresponds to the 7-finger discrimination test. (C) Electrodes stimulated corresponding to each finger are shown. Session-to-session changes are denoted as + (added electrode) or X (removed electrode).

To assess the consistency of finger projected fields within a session, we had the subject report the finger where he experienced the sensation elicited by stimulation through each electrode or electrode grouping (Fig. 3A). For all experimental blocks, the subject was stimulated in one finger at a time (or none), and asked to indicate the perceived finger (or none). For all blocks, the four right fingers and left thumb were used. The penultimate session assessed the four right fingers, left thumb, and left index. The final session additionally incorporated the left middle finger, including all 7 stimulated fingers, since the middle finger percept had recently been observed (Fig. 3B).

One, two, or three electrode combinations were mapped to each finger (Fig. 3C); stimulation through multiple electrodes was performed to provide more intense percepts. In each session, electrodes that evoked clearly localized percepts were selected before testing and reviewed with the subject; selected electrodes were highly consistent across sessions. Indeed, a nearly identical set of channels was mapped to the four fingers of the right hand and the left thumb throughout this experiment.

The subject was nearly perfectly consistent in his discrimination of stimulated finger, with a mean block accuracy of $99.0 \%$ across 6 sessions spanning 25 weeks of testing (Fig. 3A, blue dots). In separate 
medRxiv preprint doi: https://doi.org/10.1101/2020.05.29.20117374; this version posted June 8, 2020. The copyright holder for this preprint

(which was not certified by peer review) is the author/funder, who has granted medRxiv a license to display the preprint in perpetuity.

All rights reserved. No reuse allowed without permission.

blocks, we tested a fixed subset of electrodes for 3 weeks after the first day of testing, to assess the stability of their projected fields over that period (Fig. 3A, orange dots). This test was only carried out during the 5-finger tests. The four right-finger sites yielded perfect performance over these blocks, but the left thumb sites did not elicit detectable sensations for two sessions (but partially recovered in the last such session).

\section{Stability of projected field maps over study period}

Each electrode was stimulated multiple times over the course of the study, permitting an evaluation of the consistency of the projected fields across sessions. Of the 96 implanted electrodes, 50 (52.1\%) elicited a percept each time they were stimulated and most (94/96 or 97.9\%) elicited a percept at least once during the study.

The modal projected region for each electrode was reported on $75.8 \%$ of trials $(\mathrm{p}<0.001$, permutation test, mean null prevalence $=44.4 \%$ ), while one of the two most common regions was reported on $88.0 \%$ of trials $(\mathrm{p}<0.001$, permutation test, mean null prevalence $=61.4 \%)$. These metrics are consistent with our qualitative observation that large patterns of coverage and somatotopic ordering remained consistent throughout the study but that there was moderate amount of spatial jitter across days.

As an additional metric of assessing projected field consistency, we computed the Sorensen index (40):

$$
S_{\text {elec }}=\frac{N}{N-1}\left(1-\frac{P}{\sum_{i=1}^{P} p_{i}}\right)
$$

where $N$ is the number of stimulation events on a given electrode, $P$ is the total number of reported projected fields across all stimulation events, and $p_{i}$ is the number of times a sensation was elicited at a given location. The metric ranges from 0 (percepts never overlapped) to 1 (projected fields were identical across all trials). Of the 87 electrodes that elicited a percept at least twice over the testing period, the median similarity in the projected field from each electrode was $63.9 \%(\mathrm{p}<0.001$, permutation test with shuffled within-day labels, median null similarity $=17.9 \%$ ).

While most electrodes evoked stable percepts, two finger percepts emerged several months into testing on the left hemisphere array. A left-hand index percept that was felt on the first testing session (month 1) was felt again eight months later, with several null testing sessions in between. Additionally, several new middle finger percepts were reported nine months into testing, again after several sessions of no sensation.

\section{Spatial extent of projected fields}

In an attempt to estimate not just the location but also the size of the projected fields, the participant marked the projected fields on a hand image using a computer trackpad. Projected fields from all 96 electrodes were queried in this way, at intensities of 20,40,60, and $80 \mu \mathrm{A}$. During this process, the participant was blinded to both the intensity and the electrode that was stimulated, and stimulation condition was ordered pseudorandomly. Example projected fields are shown in Fig. 4A-B. Projected field size was quantified using the pixel count of the marking, with interior areas filled (i.e., area rather than circumference), normalized to the fingertip size. The median size of all projected fields (across all electrodes and stimulation intensities) was $20 \%$ larger than the fingertip area (Fig. 4C). 


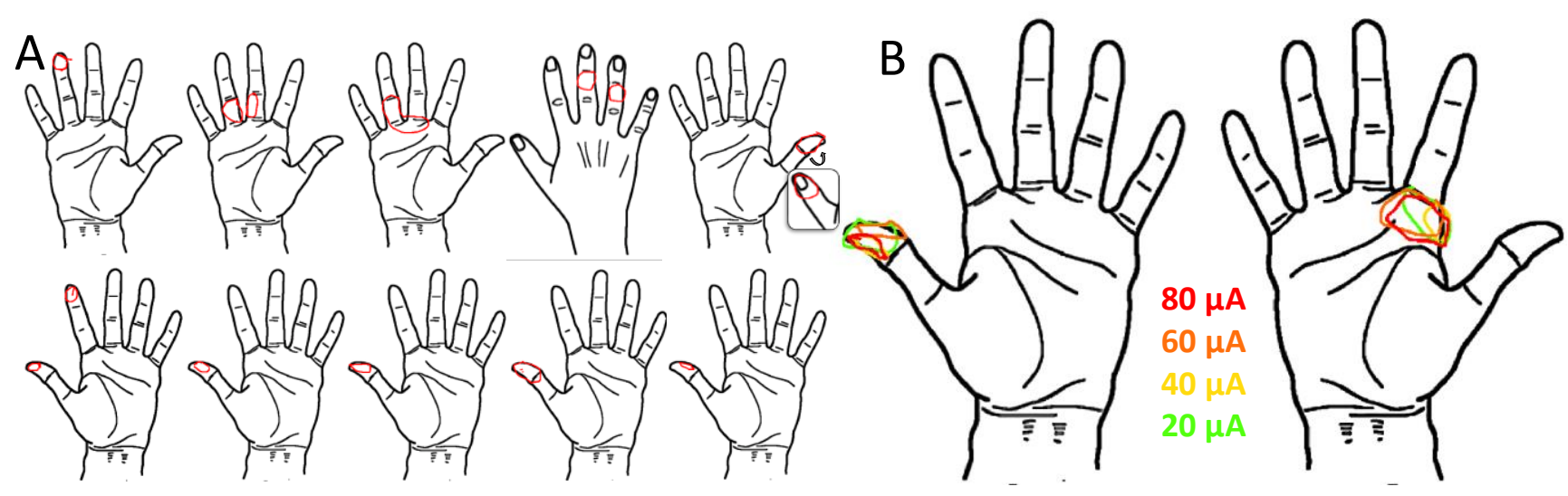

Example projected fields, $80 \mu \mathrm{A}$

Projected field overlap, example electrodes

C

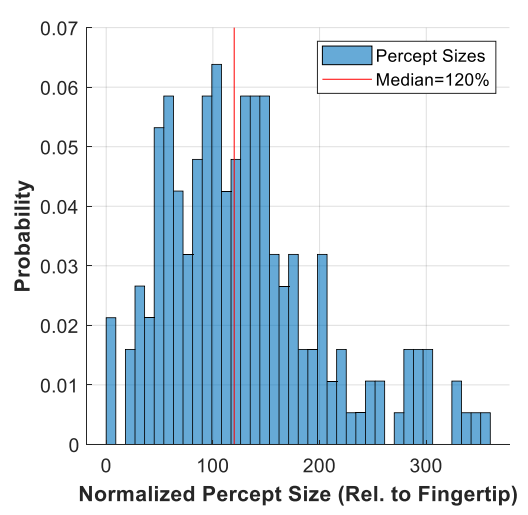

D

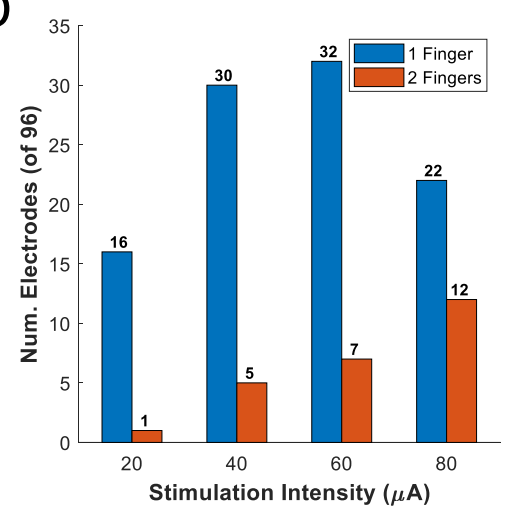

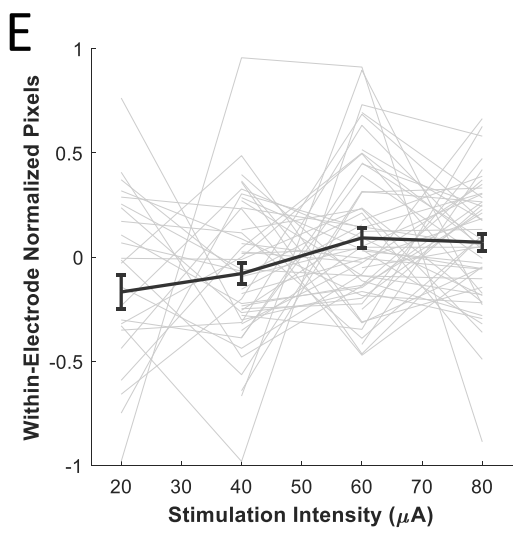

Figure 4. Drawn Projected Fields. (A) Example projected fields (elicited at $80 \mu \mathrm{A}$ ) drawn by the participant. All drawn hands were elicited on a single electrode. The top right example elicited sensation on both sides of the right thumb. In the bottom right hand, small dots within the projected field indicate "dull pencil point" sensations at those specific points. (B) Projected fields for four stimulation intensities through 2 different electrodes. (C) Distributions of projected field laterality (top) and number of elicited finger sensations (bottom). (D) Distributions of mean-normalized pixel counts for the four intensities tested. (E) Distribution of projected field sizes, with outliers omitted. Sizes are normalized to the number of pixels in the fingertip of the index finger. The median normalized percept size of $120 \%$ is indicated by the red line.

The vast majority of percepts were reported to be contralateral to the stimulating electrode, with a few percepts experienced on the ipsilateral hand or on both hands- $7.7 \%$ of felt percepts had at least some ipsilateral component. No ipsilateral components of projected fields overlapped with projected fields at other intensities on the same electrode. Projected fields that included finger areas were confined to either a single digit or two with the proportion of individual finger percepts ranging from 16/17 (94.1\%) at 20 $\mu \mathrm{A}$ to $22 / 34(64.7 \%$ ) at $80 \mu \mathrm{A}$ (see Fig. 4D). The projected field size increased modestly with increase in stimulation amplitude (Fig. 4E), confirmed via 2-way ANOVA across electrode $(\mathrm{p}=3.2 \mathrm{e}-10)$ and stimulation intensity $(\mathrm{p}=0.002)$. It is notable that despite a fourfold increase in current between minimum and maximum intensities, sizes only range from $16 \%$ below the mean at $20 \mu \mathrm{A}$ to $9 \%$ above the mean at $60 \mu \mathrm{A}$. 


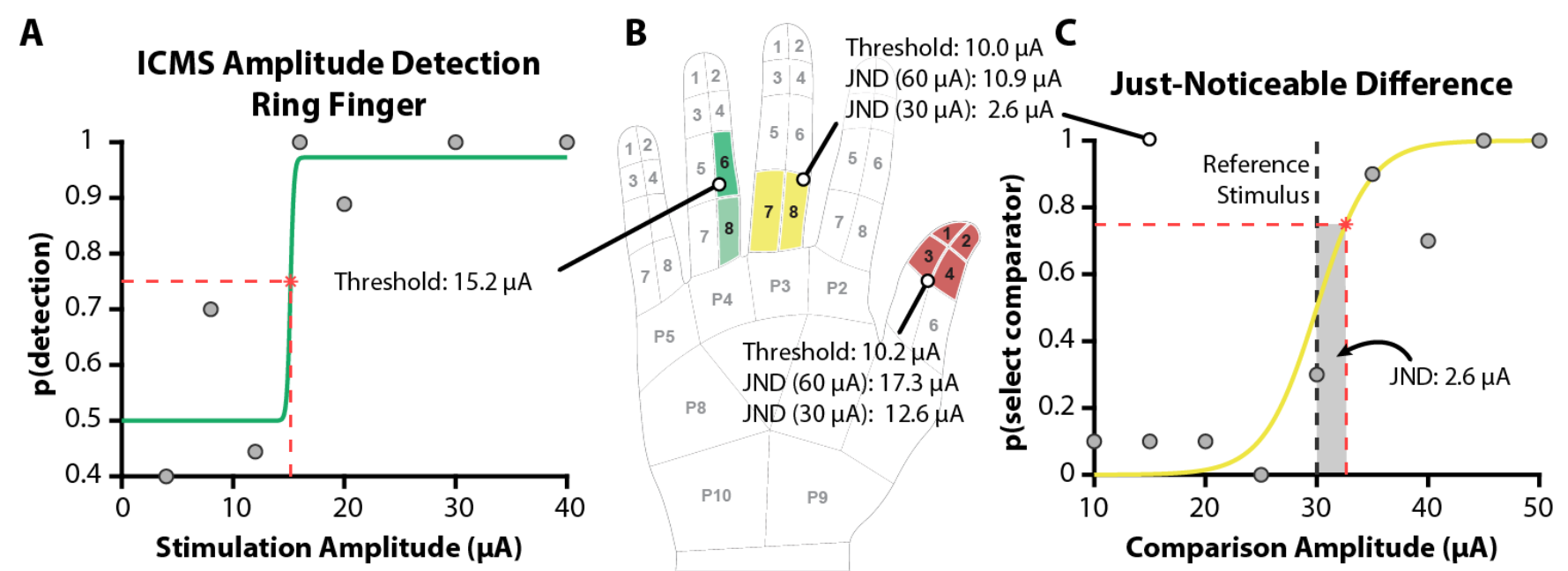

Figure 5. Intracortical microstimulation detection thresholds and JNDs. (A) Example psychometric curve from a stimulation $2 A F C$ detection task for a single electrode mapping to the ring finger, fit to the proportion of detected stimuli at each amplitude. (B) Examples of sensory locations where detection thresholds and just-noticeable differences (JND) were collected. Stimulation on the electrode mapped to the ring finger was perceived in segment 6 (green). In this example, the electrode mapped to the middle finger activated segments 7-8 (yellow) on the middle finger as well as segment 8 (green) on the ring finger. The thumb perception was localized to segments 1-4 (red). (C) Example data from the ICMS amplitude 2AFC $J N D$ task on the middle finger, with psychometric curve fit to the proportion of trials in which the participant chose the comparator stimulus (correctly when greater than reference, incorrectly when below).

\section{Psychophysical Percept Quantification}

We measured the detection threshold and the just-noticeable difference (JND) in ICMS amplitude for a subset of the implanted electrodes using a two-alternative forced-choice (2AFC) paradigm. In the 2AFC paradigm, the participant reported which of two intervals a stimulus was present. Similarly for the JND experiment, two stimulus intervals were presented to the participant, who then verbally responded which interval contained the more intense stimulus.

We selected an exemplary electrode from each of the three stimulating arrays implanted in the somatosensory cortex to estimate the detection threshold. From the full psychophysical $2 \mathrm{AFC}$ sweep, the estimated ICMS amplitude detection thresholds were $9.4 \mu \mathrm{A}$ (base of the right index finger), $15.2 \mu \mathrm{A}$ (right ring finger, Fig. 5A-B), and $25.9 \mu \mathrm{A}$ (left thumb fingertip).

To estimate the JND for ICMS amplitude, we selected an exemplary electrode from each implanted stimulating array in the left hemisphere (right middle finger, right thumb fingertip, Fig. 5B). During each $2 \mathrm{AFC}$ trial, we used either a low $(30 \mu \mathrm{A})$ or high $(60 \mu \mathrm{A})$ reference stimulus in one of the two intervals. In this experiment, the JND is defined as the minimum change in ICMS amplitude necessary for the participant to reliably (probability of being correct is 0.75 ) identify the more intense stimulus (Fig. 5C). The mean JND was $10.8 \mu \mathrm{A}$ for all electrodes tested.

\section{Discussion}

Restoring tactile sensation is integral to creating a closed-loop BMI. Dexterous neuroprostheses will need to deliver reliable and localized sensory percepts to patients, with emphasis on fingertips given their role in object manipulation (5). To date, ICMS has proven reliable in delivering hand percepts in NHPs and humans but has lacked specificity for fingertip sensations. Here, we demonstrate that: (i) fingertip sensations could be elicited for six fingertips (seven total fingers) across both hands from three total microelectrode arrays implanted bilaterally; (ii) intraoperative functional mapping can help target 
medRxiv preprint doi: https://doi.org/10.1101/2020.05.29.20117374; this version posted June 8, 2020. The copyright holder for this preprint

(which was not certified by peer review) is the author/funder, who has granted medRxiv a license to display the preprint in perpetuity.

All rights reserved. No reuse allowed without permission.

finger areas; (iii) projected field sizes are relatively focal, on average just larger than a finger segment; (iv) projected field size and location were very stable within testing sessions and more moderately stable over a year of testing; and (v) ICMS detection thresholds in this fingertip area were comparable to previous studies with more basal finger percepts.

We utilized a novel intraoperative ECoG sensory mapping approach to improve implant finger targeting, with ECoG placement guided by a combination of structural anatomical landmarks and pre-operative fMRI imaging. Although the medial-lateral somatotopy is well established (41-45), targeting specific fingers along that axis poses difficulty given the unique anatomy of each patient. In addition, there is a perpendicular axis for within-digit representations (46) which poses an additional hurdle for targeting the fingertip of a desired finger. Microelectrode array studies in NHPs and human patients typically implant based on known landmarks $(11,47)$, or pre-operative functional imaging $(15,16)$. However, intra-digit somatotopic anatomy $(46,48)$ has not been explored for closed-loop BMIs. A meeting of Brodmann's Area 1 (BA1) and BA2 fingertip representations at the area boundary has been established (49) but the exact boundary location is variable between individuals and cannot be ascertained without neurophysiology or pathology (50). The projected fields elicited in our participant are generally consistent with a recent cortical stimulation study demonstrating a caudal fingertip cortical location (51).

The coverage, focality, and overlap of ICMS percepts are key considerations for future sensory BMIs. The median percept size in our survey measurements included 1.40 finger segments, comparable to the percept size estimate of $120 \%$ of fingertip size when marked manually. This is similar to a recent study where ICMS through MEAs yielded percepts of roughly 1.15 finger segments, compared to 2.21 for micro-ECoG and 9.56 for standard ECoG (52). In our study, we found that an average of 2.2 electrodes mapped per finger or palm area, with a maximum of 11.7 electrodes stimulating one particular palmar region. The high variance in this redundancy metric is due to a combination of edge effects (i.e., representations may not fall squarely in the array footprint) and heterogeneity in electrode density; the side of the arrays toward the central sulcus were more densely populated with electrodes. Overall, this study demonstrates the ability to cover a large portion of hand finger sensory area with focal percepts via small $(4 \times 2.4 \mathrm{~mm})$ micro-electrode arrays.

We also demonstrated a small but significant relationship between stimulation intensity and projected field size in the percept drawing task. Previous work has demonstrated a stronger linear relationship of applied stimulation current and perceived intensity (15). Our work suggests that this relationship also includes a significant, but more modest, change in the size of the perceived projected field (Fig. 3D), which suggests BMI researchers could scale intensity of stimulation to a given projected field without significantly increasing overlap.

The ICMS percepts demonstrated a large degree of intra-day stability, with moderate inter-day stability, as evidenced by performance on a finger discrimination task and the presence of the modal hand region in $75.8 \%$ of trials across electrodes. This stability is contrasted by other fluctuations, including the appearance of a left middle finger percept 9 months into testing. The emergence of percepts over the course of the first year of testing, though we observed this to a much smaller degree, is consistent with a recent human ICMS study (53). It is likely that this emergence of percepts over the course of the study is related to the decrease of stimulation thresholds over a similar timespan (54). There are a many factors that may underlie these percept map changes, including changes in the electrode-tissue interface or cortical plasticity induced by the study (55).

We estimated the ICMS amplitude detection threshold and JND in a subset of exemplary electrodes (Fig. 5). Although we only thoroughly evaluated a few electrodes to determine detection threshold and 
medRxiv preprint doi: https://doi.org/10.1101/2020.05.29.20117374; this version posted June 8, 2020. The copyright holder for this preprint

(which was not certified by peer review) is the author/funder, who has granted medRxiv a license to display the preprint in perpetuity.

All rights reserved. No reuse allowed without permission.

JND, our results show good alignment with previous findings in non-human primates (56) and humans (15). Our results suggest that the ICMS amplitude detection threshold is slightly lower (9.4-25.9 $\mu \mathrm{A})$ than the median detection threshold values in the fingertips of non-human primates (56), but in general our results fall within the reasonable range of previously reported detection thresholds $(56,15)$.

Importantly, our results of ICMS amplitude detection thresholds in the fingertip $(10.2 \mu \mathrm{A}$ in the right thumb and $25.9 \mu \mathrm{A}$ in the left thumb, Fig. 5B) are similar to values reported in the palmar regions and base of the fingers in our results as well as in previous findings (15). These findings suggest that the minimum ICMS amplitude needed to elicit sensation in the fingertips of a human subject is similar to the stimulation value needed to elicit percepts in other locations of the finger or hand. Our observed ICMS JNDs (mean: $10.8 \mu \mathrm{A}$ ) are comparable to previously reported values $(15.4 \mu \mathrm{A} \pm 3.9 \mu \mathrm{A})(15)$. Given that we did not run JNDs on all electrodes due to time limitations, bias in electrode selection very likely accounts for this difference.

There were several limitations of the current study that point to new research directions. We only implanted one subject, which limits the generalizability of the study. However, the successful implantation of fingertip regions in both hemispheres suggests that our intraoperative mapping approach could generalize to other participants with retained sensation, and that human fingertip anatomy may be accessible on the cortical surface. For individuals with more limited retained sensation, intraoperative cortical stimulation would be a possible alternative. While we were able to elicit fingertip percepts across three different arrays, non-fingertip percepts still accounted for the majority of percept-eliciting electrodes. Future studies will need to improve upon our intraoperative targeting approach while maintaining flexibility to account for individual anatomy and retained sensation (or lack thereof).

Fingertip sensory restoration is a critical step in creating dexterous closed-loop brain-machine interface prostheses for patients with spinal cord injury and related disorders. Our results build upon prior work in NHP and humans to demonstrate that not only can sensory percepts be reliably elicited, but that they can be targeted to fingertip cortical representations. The results from the current study demonstrate stability of percepts across time, with minimal intra-electrode variability. Combining ICMS fingertip stimulation with robust hand and finger control could pave the way to dexterous prosthesis control in the future.

\section{Materials and Methods}

\section{Clinical study design}

This study was conducted under Investigational Device Exemption (IDE, 170010) by the Food and Drug Administration (FDA) for the purpose of evaluating bilateral sensory and motor capabilities of microelectrode array implants. The study protocol was approved by the FDA, the Johns Hopkins Institutional Review Board (JH IRB) and NIWC Pacific IRB and is a registered clinical trial (NCT03161067). Recruitment targeted individuals with complete or incomplete quadriplegia resulting from spinal cord injury. The consented participant was affected by a C5 (Sensory) / C6 (Motor) ASIA B spinal cord injury with some retained movement with weakness in the upper arms and wrist and near total paralysis in the fingers bilaterally. Peripheral somatosensation was reported as intact by the participant, with some deficits noted in pinprick examination preoperatively. The participant engages in many daily activities which use his residual upper arm motor and sensory capabilities (e.g., pushing his wheelchair).

\section{Pre-operative functional imaging and implant planning}


medRxiv preprint doi: https://doi.org/10.1101/2020.05.29.20117374; this version posted June 8, 2020. The copyright holder for this preprint

(which was not certified by peer review) is the author/funder, who has granted medRxiv a license to display the preprint in perpetuity.

All rights reserved. No reuse allowed without permission.

Prior to surgery, the participant was anatomically and functionally mapped in a high resolution 7T MRI scanner. Structural MRI was segmented using freely available Freesurfer software (57), which included a segmentation based on gyral and sulcal anatomy. Pre- and postcentral gyri were marked in this segmentation were confirmed visually by the team and used to identify putative hand knobs for motor array targeting. Functional MRI (fMRI) was captured during several sensory and motor tasks to estimate the area of cortex subserving the target upper limb representations. BOLD signals recorded in the fMRI were contrasted between rest and active periods in a block-based design as described in (58). Motor tasks included physical, imagined, and attempted movements spanning from the upper arm to individual finger movements. Hemodynamic responses to motor behaviors confirmed the hand knob location from structural imaging and provided some sub-region targeting information. Sensory mapping was conducted under fMRI using a custom pulley-based system for mechanically stimulating individual fingers. Finger sensory activity was observed in the postcentral gyrus lateral to the hand knob and motor activity, consistent with prior reports of the relative finger motor and sensory representations in humans (59).

\section{Intraoperative functional mapping}

MRI and fMRI maps of sensorimotor function were used to target the placement of high-density electrocorticographic (ECoG) grids ( $1 \mathrm{~mm}$ contacts, $3 \mathrm{~mm}$ spacing) intraoperatively. The participant was awakened for the mapping portion of the surgery so that he could be instructed to carry out the necessary sensory or motor tasks. Recordings were taken from the ECoG grids in one hemisphere at a time in a sensory configuration (i.e., covering the postcentral gyrus) or a motor configuration (i.e., covering the precentral gyrus) for vibrotactile stimulation or attempting movements, respectively. Real-time mapping of high gamma (70-110 Hz) modulation was performed using WebFM, a custom BCI2000-based plugin (37) enabling online signal processing and visualization. Vibration was provided via coin cell motors affixed individually to the participants fingertips and programmatically driven by an Arduino microcontroller at $60 \mathrm{~Hz}$. Movement was cued auditorily using BCI2000. Maps from movements were difficult to interpret in real-time due to variable performance by the awakened participant. Maps from vibrotactile stimulation of individual fingers were used to inform the placement of the stimulating MEAs within specific finger representations in somatosensory cortex.

\section{Neural stimulation and recording}

Neurostimulation was delivered via the Cerestim R96 (Blackrock Microsystems; Salt Lake City, UT), controlled by either the manufacturer-provided software or MATLAB scripts messaging a custom APIcalling interface software module. The custom interface module was written to reject stimulation parameters outside the studies safety parameters, governed by prior work with nonhuman primates (60). Neural recording and impedance measurements were performed using the NeuroPort system (Blackrock Microsystems); see Fig. S1. During the experiments described in this report, recording was used solely for verification of proper connection and safety monitoring.

For a 4-month period (months 3-7 post surgery), we switched the cable interfacing with the right hemisphere stimulating array. The difference in cables was the current return path - the new cable had a current return path through the implanted reference wire, as opposed to ground (i.e., the patient pedestal). It became clear that the evoked percepts this while using the new cable were much more variable than the evoked percepts while using the original ground return path cable, and we switched the cable back to the ground return path cable. Qualitative surveys using this data were discarded from analysis in this study.

Projected field location surveys 
medRxiv preprint doi: https://doi.org/10.1101/2020.05.29.20117374; this version posted June 8, 2020. The copyright holder for this preprint

(which was not certified by peer review) is the author/funder, who has granted medRxiv a license to display the preprint in perpetuity.

All rights reserved. No reuse allowed without permission.

Qualitative report of ICMS projected field location was collected in one of two ways. For most of the study, projected field size and location was approximated using verbal report of a provided map with region codes corresponding to experimenter-defined sub-portions of the hand and fingers. Projected field spatial information was collected alongside intensity and character. For the fingertip projected field size study, the participant was asked to mark his projected field on a laptop using a custom drawing application. Manual marking was used to avoid overestimating projected field size estimates with the experimenter defined regions. In all projected field estimation experiments, delivery of sensation was handled by the experimenter but managed by the participant in that he frequently requested repeat delivery of stimulation (e.g., 2-3 times) to better report the locations and intensities.

In analyzing the projected field size, a 2-way ANOVA model was used with electrode identity and stimulation intensity as factors. Inputs to this model were pixel counts of projected fields with several inclusion and exclusion criteria: (1) we only considered contralateral projected fields, (2) null responses were not considered, (3) "outlier" projected fields were discarded if their area was greater than the $75^{\text {th }}$ percentile plus 1.5 interquartile ranges, (4) projected fields with no pixel overlap between any of the four stimulated intensities were discarded.

\section{Finger discrimination task}

The participant performed a blinded finger discrimination task to quantify stimulation percept accuracy. The participant was asked to determine the finger percept stimulated by ICMS to randomly selected, pre-determined electrodes. Trials were pseudorandomly ordered across all conditions, with a total of 10 trials per condition.

On the first day of the task, groups of electrodes were selected for stimulation based upon their projected field locations. The participant was briefly trained with the set of electrodes by being introduced to the electrode's elicited sensation and confirming its location on the desired finger. The task then proceeded as a fixed-choice reporting task, where the participant was instructed to name one of the mapped fingers or say that no finger was stimulated. The participant was blinded to results during the testing.

On subsequent testing days, the task proceeded in two phases. First, the Day 1 finger-to-electrode mappings were used for one block without change to ascertain the stability of stimulation parameters and resulting perception over weeks. Second, fingers discriminated with over $10 \%$ error were identified for re-selection of electrodes, performed via sweep of several candidate electrodes and verification that the new stimulation could be differentiated from the stimulation of other electrodes. Once a new set of electrodes was chosen, the task was run again to observe peak within-day performance.

\section{Detection thresholds and just-noticeable difference estimation}

Detection thresholds and JNDs were estimated using a 2AFC testing paradigm. The detection thresholds were calculated for 3 electrodes, one on each implanted stimulating array, and the JND was calculated for 2 electrodes, one on each implanted stimulating array in the left hemisphere. The participant looked at a cross on a monitor while two intervals were presented. The color of the cross changed to indicate the unique intervals. For the detection threshold experiment, each trial consisted of a $0.5 \mathrm{~s}$ ICMS presentation in one of the two $1 \mathrm{~s}$ intervals. The participant verbally indicated during which interval he perceived a sensation in his hand. The detection threshold is defined as the ICMS amplitude needed to elicit an accurate response from the participant with an accuracy of 75\%. Each ICMS amplitude was presented 1020 times, based on time available. 
medRxiv preprint doi: https://doi.org/10.1101/2020.05.29.20117374; this version posted June 8, 2020. The copyright holder for this preprint

(which was not certified by peer review) is the author/funder, who has granted medRxiv a license to display the preprint in perpetuity.

All rights reserved. No reuse allowed without permission.

Similarly, the ICMS amplitude JND experiment contained two intervals during each trial. One of the two reference stimuli $(0.5 \mathrm{~s}, 100 \mathrm{~Hz}$, low: $30 \mu \mathrm{A}$, high: $60 \mu \mathrm{A})$ were presented in one of the trial intervals. The other interval contained a $0.5 \mathrm{~s}, 100 \mathrm{~Hz}$ ICMS pulse train with an amplitude ranging $\pm 20 \mu \mathrm{A}$, with a resolution of $5 \mu \mathrm{A}$, from the reference stimulus. Each amplitude was presented 10 times for a given reference stimulus. The JND is defined as the minimum ICMS amplitude needed to detect a difference from a reference stimulus with an accuracy of $75 \%$.

To estimate thresholds for the JND experiment, we used a rapid adaptive 3 down- 1 up staircase psychophysics method for estimating the detection threshold at $79.4 \%$ (61). The adaptive staircase method is implemented by decreasing the stimulus level until there is no discernable percept, at which point a 'reversal' occurs and the stimulation level increases again. The stimulus level increases with every incorrect response form the participant. To employ the 3 down-1 up paradigm, 3 correct responses in a row at a given stimulus level lead to a decrease in the stimulus level (61). A reversal occurs whenever slope of the staircase changes and the detection threshold is calculated by averaging the stimulus level at all reversals (61). Each electrode was tested until 5 reversals occurred. 
medRxiv preprint doi: https://doi.org/10.1101/2020.05.29.20117374; this version posted June 8, 2020. The copyright holder for this preprint

(which was not certified by peer review) is the author/funder, who has granted medRxiv a license to display the preprint in perpetuity.

All rights reserved. No reuse allowed without permission.

\section{References and Notes:}

1. C. Ghez, J. Gordon, M. F. Ghilardi, Impairments of reaching movements in patients without proprioception. II. Effects of visual information on accuracy, J. Neurophysiol. 73, 361-372 (1995).

2. R. S. Johansson, C. Häger, L. Bäckström, Somatosensory control of precision grip during unpredictable pulling loads. III. Impairments during digital anesthesia, Exp. Brain Res. 89, 204-213 (1992).

3. A. G. Richardson, M. A. Attiah, J. I. Berman, H. I. Chen, X. Liu, M. Zhang, J. Van der Spiegel, T. H. Lucas, The effects of acute cortical somatosensory deafferentation on grip force control, Cortex 74, 1-8 (2016).

4. J. C. Rothwell, M. M. Traub, B. L. Day, J. A. Obeso, P. K. Thomas, C. D. Marsden, Manual motor performance in a deafferented man, Brain 105, 515-542 (1982).

5. R. S. Johansson, J. R. Flanagan, Coding and use of tactile signals from the fingertips in object manipulation tasks, Nat. Rev. Neurosci. 10, 345-359 (2009).

6. M. I. Christel, S. Kitzel, C. Niemitz, How Precisely Do Bonobos (Pan paniscus) Grasp Small Objects?, Int. J. Primatol. 19, 165-194 (1998).

7. R. S. Johansson, A. B. Vallbo, Tactile sensibility in the human hand: relative and absolute densities of four types of mechanoreceptive units in glabrous skin, J. Physiol. 286, 283-300 (1979).

8. G. Corniani, H. P. Saal, Tactile innervation densities across the whole body, bioRxiv , 2020.04.27.063263 (2020).

9. B. P. Delhaye, K. H. Long, S. J. Bensmaia, Neural Basis of Touch and Proprioception in Primate Cortex, Compr. Physiol. 8, 1575-1602 (2018).

10. T. Callier, N. W. Brantly, A. Caravelli, S. J. Bensmaia, The frequency of cortical microstimulation shapes artificial touch, Proc. Natl. Acad. Sci. (2019), doi:10.1073/pnas.1916453117.

11. J. E. O’Doherty, M. A. Lebedev, P. J. Ifft, K. Z. Zhuang, S. Shokur, H. Bleuler, M. A. L. Nicolelis, Active tactile exploration using a brain-machine-brain interface, Nature 479, 228-231 (2011).

12. R. Romo, A. Hernández, A. Zainos, E. Salinas, Somatosensory discrimination based on cortical microstimulation, Nature 392, 387-390 (1998).

13. G. A. Tabot, J. F. Dammann, J. A. Berg, F. V. Tenore, J. L. Boback, R. J. Vogelstein, S. J. Bensmaia, Restoring the sense of touch with a prosthetic hand through a brain interface, Proc. Natl. Acad. Sci. U. S. A. 110, 18279-18284 (2013).

14. S. Kim, T. Callier, G. A. Tabot, R. A. Gaunt, F. V. Tenore, S. J. Bensmaia, Behavioral assessment of sensitivity to intracortical microstimulation of primate somatosensory cortex, Proc. Natl. Acad. Sci. U. S. A. 112, 15202-15207 (2015).

15. S. N. Flesher, J. L. Collinger, S. T. Foldes, J. M. Weiss, J. E. Downey, E. C. Tyler-Kabara, S. J. Bensmaia, A. B. Schwartz, M. L. Boninger, R. A. Gaunt, Intracortical microstimulation of human somatosensory cortex, Sci. Transl. Med. 8, 361ra141-361ra141 (2016).

16. M. Armenta Salas, L. Bashford, S. Kellis, M. Jafari, H. Jo, D. Kramer, K. Shanfield, K. Pejsa, B. Lee, C. Y. Liu, R. A. Andersen, R. Romo, Ed. Proprioceptive and cutaneous sensations in humans elicited by intracortical microstimulation, eLife 7, e32904 (2018).

17. S. V. Hiremath, E. C. Tyler-Kabara, J. J. Wheeler, D. W. Moran, R. A. Gaunt, J. L. Collinger, S. T. Foldes, D. J. Weber, W. Chen, M. L. Boninger, W. Wang, Human perception of electrical stimulation on the surface of somatosensory cortex, PLOS ONE 12, e0176020 (2017). 
medRxiv preprint doi: https://doi.org/10.1101/2020.05.29.20117374; this version posted June 8, 2020. The copyright holder for this preprint

(which was not certified by peer review) is the author/funder, who has granted medRxiv a license to display the preprint in perpetuity.

All rights reserved. No reuse allowed without permission.

18. B. Lee, D. Kramer, M. Armenta Salas, S. Kellis, D. Brown, T. Dobreva, C. Klaes, C. Heck, C. Liu, R. A. Andersen, Engineering Artificial Somatosensation Through Cortical Stimulation in Humans, Front. Syst. Neurosci. 12 (2018), doi:10.3389/fnsys.2018.00024.

19. D. R. Kramer, M. B. Lee, M. Barbaro, A. S. Gogia, T. Peng, C. Liu, S. Kellis, B. Lee, Mapping of primary somatosensory cortex of the hand area using a high-density electrocorticography grid for closed-loop brain computer interface., J. Neural Eng. (2020), doi:10.1088/1741-2552/ab7c8e.

20. M. C. Dadarlat, J. E. O’Doherty, P. N. Sabes, A learning-based approach to artificial sensory feedback leads to optimal integration, Nat. Neurosci. 18, 138-144 (2015).

21. B. M. London, L. R. Jordan, C. R. Jackson, L. E. Miller, Electrical Stimulation of the Proprioceptive Cortex (Area 3a) Used to Instruct a Behaving Monkey, IEEE Trans. Neural Syst. Rehabil. Eng. 16, 32-36 (2008).

22. J. E. O’Doherty, M. Lebedev, T. L. Hanson, N. Fitzsimmons, M. A. L. Nicolelis, A brain-machine interface instructed by direct intracortical microstimulation, Front. Integr. Neurosci. 3 (2009), doi:10.3389/neuro.07.020.2009.

23. J. A. Berg, J. F. Dammann, III, F. V. Tenore, G. A. Tabot, J. L. Boback, L. R. Manfredi, M. L. Peterson, K. D. Katyal, M. S. Johannes, A. Makhlin, R. Wilcox, R. K. Franklin, R. J. Vogelstein, N. G. Hatsopoulos, S. J. Bensmaia, Behavioral Demonstration of a Somatosensory Neuroprosthesis, IEEE Trans. Neural Syst. Rehabil. Eng. 21, 500-507 (2013).

24. C. Klaes, Y. Shi, S. Kellis, J. Minxha, B. Revechkis, R. A. Andersen, A cognitive neuroprosthetic that uses cortical stimulation for somatosensory feedback, J. Neural Eng. 11, 056024 (2014).

25. J. E. O’Doherty, S. Shokur, L. E. Medina, M. A. Lebedev, M. A. L. Nicolelis, Creating a neuroprosthesis for active tactile exploration of textures, Proc. Natl. Acad. Sci. 116, 21821-21827 (2019).

26. S. N. Flesher, J. E. Downey, J. M. Weiss, C. L. Hughes, A. J. Herrera, E. C. Tyler-Kabara, M. L. Boninger, J. L. Collinger, R. A. Gaunt, Restored tactile sensation improves neuroprosthetic arm control, bioRxiv, 653428 (2019).

27. P. D. Ganzer, S. C. Colachis, M. A. Schwemmer, D. A. Friedenberg, C. F. Dunlap, C. E. Swiftney, A. F. Jacobowitz, D. J. Weber, M. A. Bockbrader, G. Sharma, Restoring the Sense of Touch Using a Sensorimotor Demultiplexing Neural Interface, Cell 0 (2020), doi:10.1016/j.cell.2020.03.054.

28. E. D’Anna, F. M. Petrini, F. Artoni, I. Popovic, I. Simanić, S. Raspopovic, S. Micera, A somatotopic bidirectional hand prosthesis with transcutaneous electrical nerve stimulation based sensory feedback, Sci. Rep. 7, 10930 (2017).

29. L. E. Osborn, A. Dragomir, J. L. Betthauser, C. L. Hunt, H. H. Nguyen, R. R. Kaliki, N. V. Thakor, Prosthesis with neuromorphic multilayered e-dermis perceives touch and pain, Sci. Robot. 3 (2018), doi:10.1126/scirobotics.aat3818.

30. J. A. George, D. T. Kluger, T. S. Davis, S. M. Wendelken, E. V. Okorokova, Q. He, C. C. Duncan, D. T. Hutchinson, Z. C. Thumser, D. T. Beckler, P. D. Marasco, S. J. Bensmaia, G. A. Clark, Biomimetic sensory feedback through peripheral nerve stimulation improves dexterous use of a bionic hand, Sci. Robot. 4 (2019), doi:10.1126/scirobotics.aax2352.

31. E. L. Graczyk, M. A. Schiefer, H. P. Saal, B. P. Delhaye, S. J. Bensmaia, D. J. Tyler, The neural basis of perceived intensity in natural and artificial touch, Sci. Transl. Med. 8, 362ra142-362ra142 (2016).

32. M. Ortiz-Catalan, B. Håkansson, R. Brånemark, An osseointegrated human-machine gateway for long-term sensory feedback and motor control of artificial limbs, Sci. Transl. Med. 6, 257re6-257re6 (2014).

33. Z. T. Irwin, K. E. Schroeder, P. P. Vu, A. J. Bullard, D. M. Tat, C. S. Nu, A. Vaskov, S. R. Nason, D. E. Thompson, J. N. Bentley, P. G. Patil, C. A. Chestek, Neural control of finger movement via intracortical brain-machine interface, J. Neural Eng. 14, 066004 (2017). 
medRxiv preprint doi: https://doi.org/10.1101/2020.05.29.20117374; this version posted June 8, 2020. The copyright holder for this preprint (which was not certified by peer review) is the author/funder, who has granted medRxiv a license to display the preprint in perpetuity. All rights reserved. No reuse allowed without permission.

34. G. Hotson, D. P. McMullen, M. S. Fifer, M. S. Johannes, K. D. Katyal, M. P. Para, R. Armiger, W. S. Anderson, N. V. Thakor, B. A. Wester, N. E. Crone, Individual finger control of a modular prosthetic limb using high-density electrocorticography in a human subject, J. Neural Eng. 13, 026017 (2016).

35. C. A. Chestek, V. Gilja, C. H. Blabe, B. L. Foster, K. V. Shenoy, J. Parvizi, J. M. Henderson, Hand posture classification using electrocorticography signals in the gamma band over human sensorimotor brain areas, J. Neural Eng. 10, 026002 (2013).

36. Y. Wang, M. S. Fifer, A. Flinker, A. Korzeniewska, M. C. Cervenka, W. S. Anderson, D. F. Boatman-Reich, N. E. Crone, Spatial-temporal functional mapping of language at the bedside with electrocorticography, Neurology, 10.1212/WNL.0000000000002525 (2016).

37. G. Milsap, M. Collard, C. Coogan, N. E. Crone, BCI2000Web and WebFM: Browser-Based Tools for Brain Computer Interfaces and Functional Brain Mapping, Front. Neurosci. (2019).

38. M. M. Bridges, M. P. Para, M. J. Mashner, Control System Architecture for the Modular Prosthetic Limb, Johns Hopkins APL Tech. Dig. 30, 217-222 (2011).

39. M. S. Johannes, J. D. Bigelow, J. M. Burck, S. D. Harshbarger, M. V. Kozlowski, T. Van Doren, An overview of the developmental process for the modular prosthetic limb, Johns Hopkins APL Tech. Dig. 30, 207-216 (2011).

40. O. H. Diserud, F. Ødegaard, A multiple-site similarity measure, Biol. Lett. 3, 20-22 (2007).

41. W. Penfield, E. Boldrey, Somatic motor and sensory representation in the cerebral cortex of man as studied by electrical stimulation, Brain 60, 389-443 (1937).

42. J. A. Maldjian, A. Gottschalk, R. S. Patel, J. A. Detre, D. C. Alsop, The Sensory Somatotopic Map of the Human Hand Demonstrated at 4 Tesla, NeuroImage 10, 55-62 (1999).

43. R. Kurth, K. Villringer, G. Curio, K.-J. Wolf, T. Krause, J. Repenthin, J. Schwiemann, M. Deuchert, A. Villringer, fMRI shows multiple somatotopic digit representations in human primary somatosensory cortex., Neuroreport 11, 1487-1491 (2000).

44. R. M. Sanchez Panchuelo, R. Ackerley, P. M. Glover, R. W. Bowtell, J. Wessberg, S. T. Francis, F. McGlone, E. Vaadia, Ed. Mapping quantal touch using 7 Tesla functional magnetic resonance imaging and single-unit intraneural microstimulation, eLife 5, e12812 (2016).

45. J. Kolasinski, T. R. Makin, S. Jbabdi, S. Clare, C. J. Stagg, H. Johansen-Berg, Investigating the Stability of Fine-Grain Digit Somatotopy in Individual Human Participants, J. Neurosci. 36, 1113-1127 (2016).

46. R. M. Sanchez-Panchuelo, J. Besle, A. Beckett, R. Bowtell, D. Schluppeck, S. Francis, Within-Digit Functional Parcellation of Brodmann Areas of the Human Primary Somatosensory Cortex Using Functional Magnetic Resonance Imaging at 7 Tesla, J. Neurosci. 32, 15815-15822 (2012).

47. T. Callier, A. K. Suresh, S. J. Bensmaia, Neural Coding of Contact Events in Somatosensory Cortex, Cereb. Cortex 29 , 4613-4627 (2019).

48. M. A. Schweisfurth, J. Frahm, R. Schweizer, Individual fMRI maps of all phalanges and digit bases of all fingers in human primary somatosensory cortex, Front. Hum. Neurosci. 8 (2014), doi:10.3389/fnhum.2014.00658.

49. J. H. Kaas, R. J. Nelson, M. Sur, C.-S. Lin, M. M. Merzenich, Multiple Representations of the Body Within the Primary Somatosensory Cortex of Primates, Science 204, 521-523 (1979).

50. S. Geyer, A. Schleicher, K. Zilles, Areas 3a, 3b, and 1 of human primary somatosensory cortex, NeuroImage 10, 63-83 (1999). 
medRxiv preprint doi: https://doi.org/10.1101/2020.05.29.20117374; this version posted June 8, 2020. The copyright holder for this preprint (which was not certified by peer review) is the author/funder, who has granted medRxiv a license to display the preprint in perpetuity. All rights reserved. No reuse allowed without permission.

51. F.-E. Roux, I. Djidjeli, J.-B. Durand, Functional architecture of the somatosensory homunculus detected by electrostimulation, J. Physiol. 596, 941-956 (2018).

52. D. R. Kramer, S. Kellis, M. Barbaro, M. A. Salas, G. Nune, C. Y. Liu, R. A. Andersen, B. Lee, Technical considerations for generating somatosensation via cortical stimulation in a closed-loop sensory/motor brain-computer interface system in humans, J. Clin. Neurosci. 63, 116-121 (2019).

53. C. Hughes, A. Herrera, R. Gaunt, J. Collinger, in Handbook of Clinical Neurology, (Elsevier, 2020), vol. 168, pp. 163181.

54. C. L. Hughes, S. N. Flesher, J. M. Weiss, J. E. Downey, J. L. Collinger, R. A. Gaunt, Neural stimulation and recording performance in human somatosensory cortex over 1500 days, medRxiv , 2020.01.21.20018341 (2020).

55. E. Fernández, B. Greger, P. A. House, I. Aranda, C. Botella, J. Albisua, C. Soto-Sánchez, A. Alfaro, R. A. Normann, Acute human brain responses to intracortical microelectrode arrays: challenges and future prospects, Front. Neuroengineering 7 (2014), doi:10.3389/fneng.2014.00024.

56. G. A. Tabot, J. F. Dammann, J. A. Berg, F. V Tenore, J. L. Boback, R. J. Vogelstein, S. J. Bensmaia, Restoring the sense of touch with a prosthetic hand through a brain interface, Proc. Natl. Acad. Sci. 110, 18279-18284 (2013).

57. B. Fischl, A. van der Kouwe, C. Destrieux, E. Halgren, F. Ségonne, D. H. Salat, E. Busa, L. J. Seidman, J. Goldstein, D. Kennedy, V. Caviness, N. Makris, B. Rosen, A. M. Dale, Automatically Parcellating the Human Cerebral Cortex, Cereb. Cortex 14, 11-22 (2004).

58. M. J. Vansteensel, E. G. M. Pels, M. G. Bleichner, M. P. Branco, T. Denison, Z. V. Freudenburg, P. Gosselaar, S. Leinders, T. H. Ottens, M. A. Van Den Boom, P. C. Van Rijen, E. J. Aarnoutse, N. F. Ramsey, Fully Implanted BrainComputer Interface in a Locked-In Patient with ALS, N. Engl. J. Med. 375, 2060-2066 (2016).

59. W. Schellekens, N. Petridou, N. F. Ramsey, Detailed somatotopy in primary motor and somatosensory cortex revealed by Gaussian population receptive fields, NeuroImage 179, 337-347 (2018).

60. K. H. Chen, J. F. Dammann, J. L. Boback, F. V. Tenore, K. J. Otto, R. A. Gaunt, S. J. Bensmaia, The effect of chronic intracortical microstimulation on the electrode-tissue interface, J. Neural Eng. 11, 026004 (2014).

61. M. R. Leek, Adaptive procedures in psychophysical research, Percept. Psychophys. 63, 1279-1292 (2001). 
medRxiv preprint doi: https://doi.org/10.1101/2020.05.29.20117374; this version posted June 8, 2020. The copyright holder for this preprint

(which was not certified by peer review) is the author/funder, who has granted medRxiv a license to display the preprint in perpetuity.

All rights reserved. No reuse allowed without permission.

Acknowledgments: First and foremost, we would like to extend a huge thank you to our incomparable study participant. In addition to being a pioneer and a critical enabler of this research, his insights into the subjective experiences of the stimulation were literally invaluable. Note that this patient is also the subject of study in manuscripts MEDRXIV/2020/116913 and MEDRXIV/2020/117036. We'd also like to thank Rob Franklin, Stephen Hou, and the staff at Blackrock Microsystems for their technical support and surgical planning insights; Chad Gordon, Teresa Wojtasiewicz, Adam Schiavi, and the surgical team at Johns Hopkins Hospital for performing the implantation; Christian Cooke, Bryanna Yeh, Zachary Koterba, and Eric Nguyen for contributing to the hardware and software infrastructure used for stimulation testing; Christopher Coogan for software support of WebFM software and processing of preoperative imaging; Leigh Hochberg for guidance on surgical approaches; Jared Wormley, Christopher Dohopolski, John Roycroft, and Matthew Johannes for MPL infrastructure design and support; Joseph O’Doherty, Spencer Kellis, Luke Bashford, Michelle Armenta-Salas, Sharlene Flesher, Robert Gaunt, John Downey, Thierri Callier, Jeff Yau, and Adam Cohen for helpful discussions about ICMS-induced perception over the course of the project. Authors on this work declare no conflicts of interest. Funding: This research was developed with funding from the Defense Advanced Research Projects Agency's (DARPA; Arlington, VA) Revolutionizing Prosthetics program (contract number N66001-10-C-4056). Development of experimental setup and support for regulatory submissions associated with this study were provided by a grant from the Alfred E. Mann Foundation. Study software infrastructure and study preparation were developed with internal funding from Johns Hopkins University Applied Physics Laboratory and Johns Hopkins University. Author contributions: PAC and FVT led the clinical study. WSA, NEC, and DPM led implantation planning and execution, and all authors contributed to implantation planning. NEC, TMT, DNC, MSF, DPM, and BAW contributed to various components of the intra-operative ECoG mapping. Experimental design and stimulation testing with implanted arrays was carried out by MSF, DPM, TMT, LEO, EAP, and FVT. Pre-operative fMRI planning and analysis was carried out by RN, WS, NFR, GLC, and PAC. MSF, EAP, and BAW wrote software for controlling stimulation or collecting responses. Manuscript preparation was led by MSF and DPM, with figures and video prepared with support from BAW, LEO, TMT, and FVT. All authors contributed to design of the experiments, interpretation of the data, and the reviewing and editing of the manuscript. Competing interests: The authors declare they have no competing interests.

\section{Supplementary Materials and Methods}

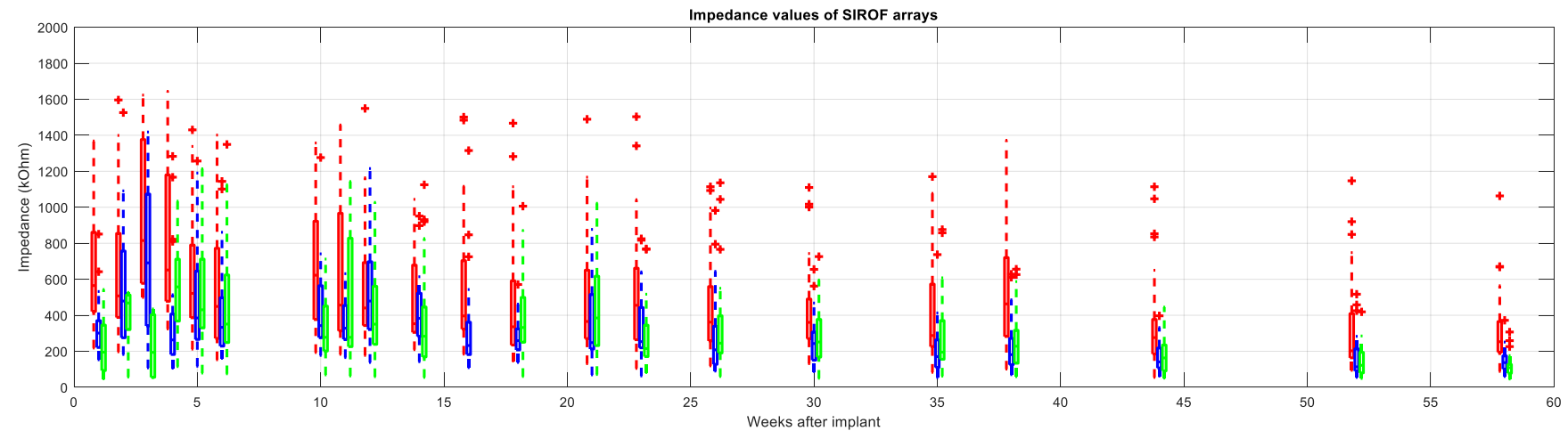

Figure S1. Impedance measurements. The impedance values for the 3 stimulating arrays (96 total electrodes) were measured over the first year of testing. Impedances are measured at $1 \mathrm{kHz}$ by delivering 
medRxiv preprint doi: https://doi.org/10.1101/2020.05.29.20117374; this version posted June 8, 2020. The copyright holder for this preprint (which was not certified by peer review) is the author/funder, who has granted medRxiv a license to display the preprint in perpetuity.

All rights reserved. No reuse allowed without permission.

a very small (10 nA peak-to-peak) current using the NeuroPort System's built-in impedance measuring capability. In the pictured boxplots, the central mark denotes the median, the edges of each box are the 25th and 75th percentile, and the whiskers extend to the most extreme data points not considered to be outliers (1.5 interquartile ranges outside the $25^{\text {th }}$ or $75^{\text {th }}$ percentiles); outliers by this criterion are instead plotted individually (+). Testing of all three arrays was always conducted within one session, but horizontal spacing has been added for visualization purposes.
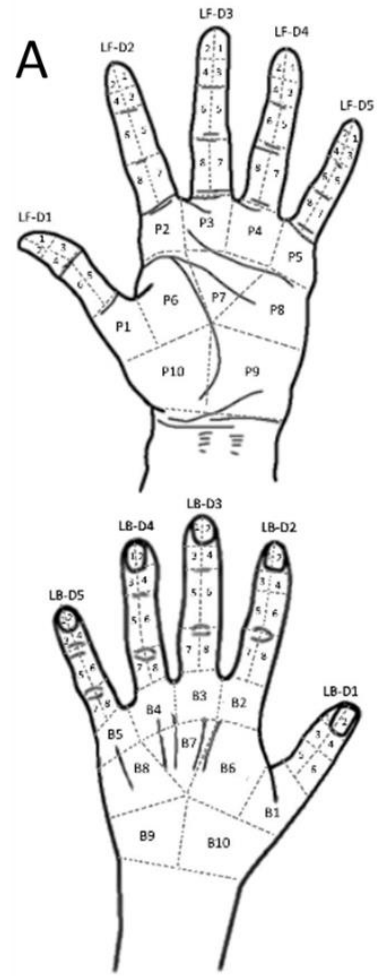
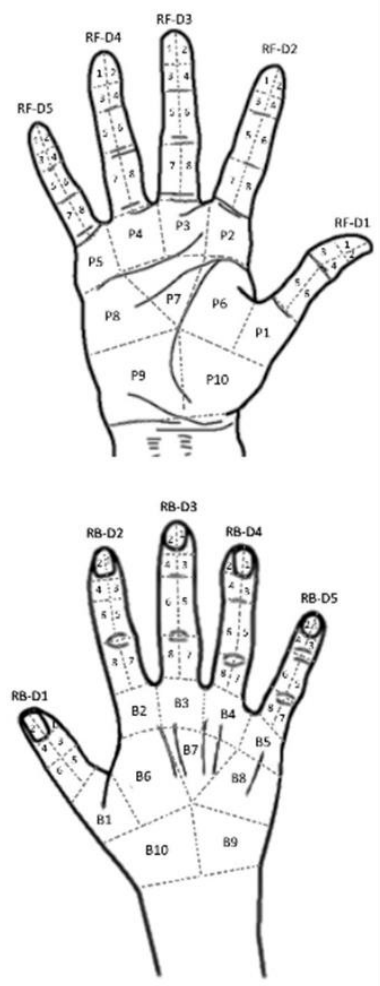
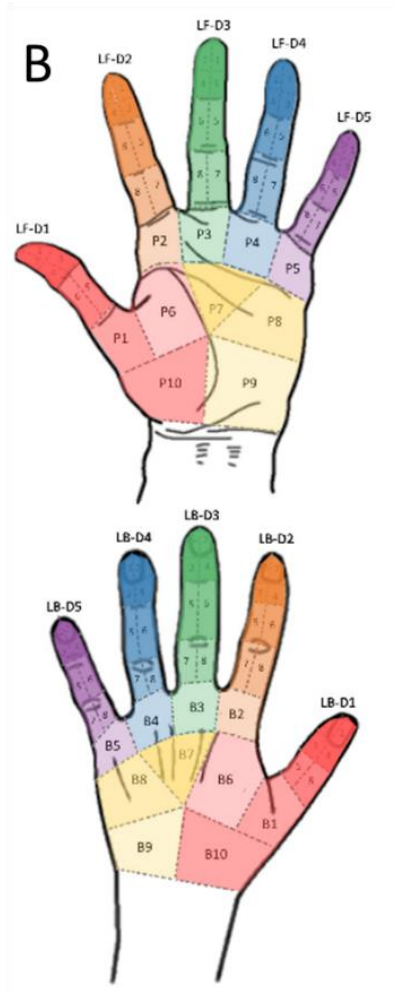
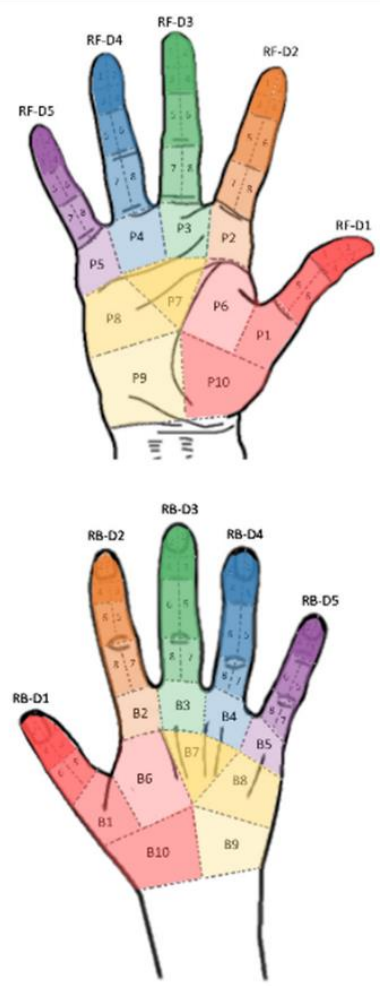

Figure S2. Qualitative Survey Reporting Map. (A) The image the subject reported his percept locations in reference to. (B) A depiction of the different finger and palmar/dorsal hand regions used for aggregation analyses. The multiple regions contained on the same phalange were lumped into a single region (i.e., rather than splitting finger regions into halves or fingertips into quarters). Palmar or dorsal hand regions were unchanged. 

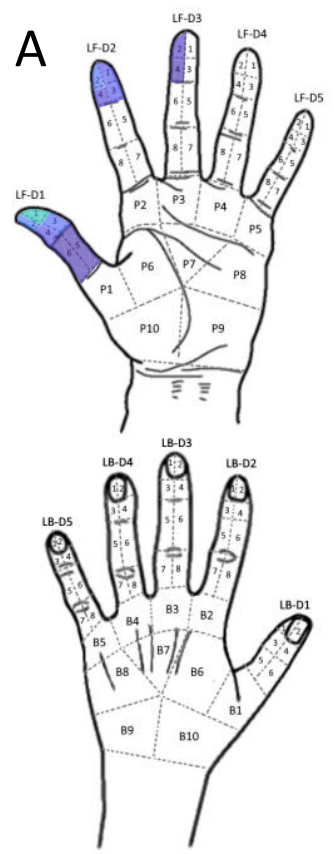
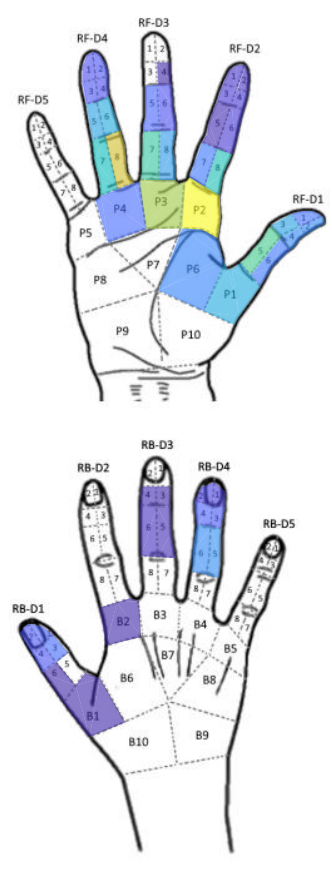
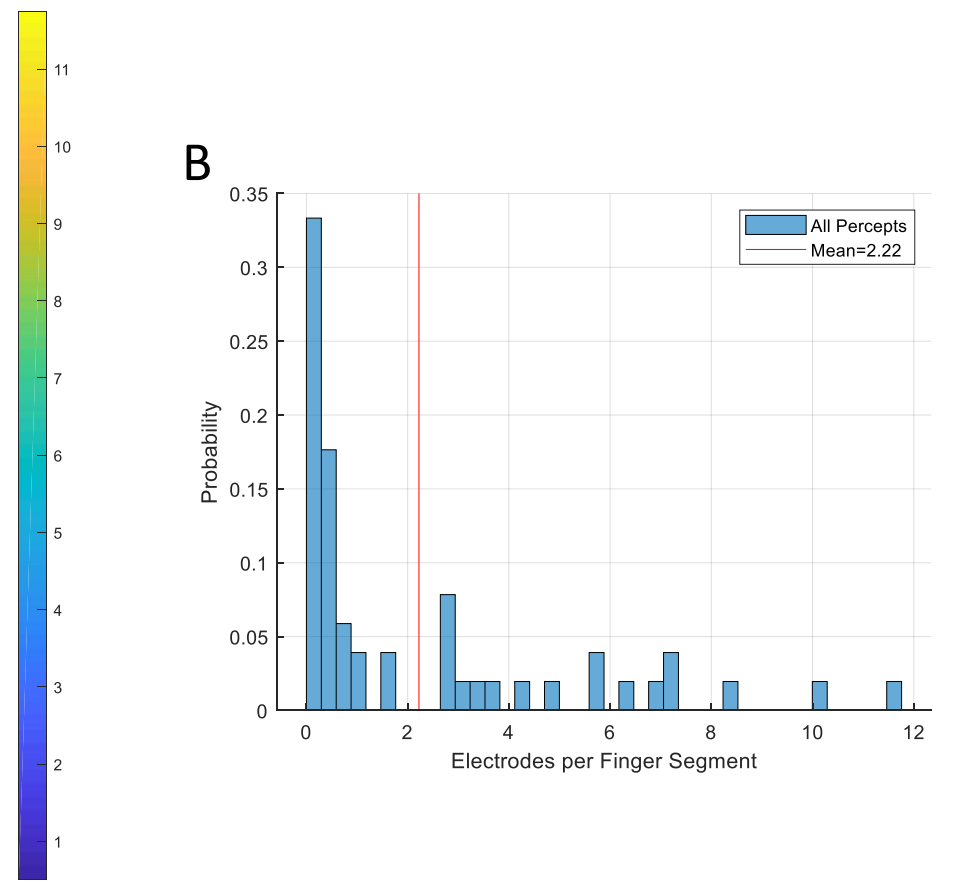

Figure S3. Coverage map drawn by prevalence across electrodes. (A) A map of the percepts elicited across all arrays is shown, with coloration determined by the number of electrodes (on average) within a day that would elicit a percept containing that region. A threshold of 0.5 average electrodes per day was used to discard low occurrence percepts from visualization. (B) A histogram of the information in (B), except aggregated over finger regions as shown in Fig. S2B. The mean value of electodes per finger segment was roughly 2.22 , with a max of 11.7 . 